\title{
Patch size and connectivity influence the population turnover of the threatened chequered blue butterfly, Scolitantides orion (Lepidoptera: Lycaenidae)
}

\author{
Atte KOMONEN $^{1 *}$, TuUli TIKKAMÄKI ${ }^{1}$, NinA MATTILA ${ }^{2}$ and JANNE S. KOTIAHO ${ }^{2,3}$ \\ ${ }^{1}$ Faculty of Forest Sciences, P.O. Box 111, FI-80101 University of Joensuu, Finland \\ ${ }^{2}$ Department of Biological and Environmental Science, P.O. Box 35, FI-40014 University of Jyväskylä, Finland \\ ${ }^{3}$ Museum of Natural History, P.O. Box 35, FI-40014 University of Jyväskylä, Finland
}

Keywords. Butterfly conservation, colonization, connectivity, extinction, Lycaenidae, metapopulation, patch size, Scolitantides orion, Sedum telephium, population turnover

\begin{abstract}
Chequered blue butterfly, Scolitantides orion (Lepidoptera: Lycaenidae) has severely declined in many parts of Europe and is currently red-listed in many countries. We studied the population structure and turnover of the species in a lake-island system in a National Park in eastern Finland over a three-year period. The incidence of the chequered blue on the suitable islands $(n=41)$ and habitat patches $(n=123)$ was high: an average of $82 \%$ of the islands and patches were occupied over the three year period. At the island scale, the annual population turnover rate was $17 \%$, with an extinction and colonization rate of $7 \%$ and $10 \%$, respectively. At the patch scale, the annual population turnover was $16 \%$, with $7 \%$ extinction and $9 \%$ colonization rate. Islands that were occupied over the three year period had a larger area of suitable habitat than islands in which turnover events were observed. At the patch scale, turnover events were observed in small and poorly connected patches. Patchy occurrence of the host plant and observed extinction-colonization dynamics suggest that the chequered blue population confirms a metapopulation structure. Although the local populations are small, the observed high patch occupancy and balanced population turnover indicates that the metapopulation is not in immediate risk of extinction.
\end{abstract}

\section{INTRODUCTION}

The chequered blue butterfly, Scolitantides orion Pallas 1771 (Lycaenidae) has a large, but discontinuous distribution across Europe (Kudrna, 2002). The species has been severely declining in northern and central parts of Europe (van Swaay \& Warren, 1999), and in Finland the species is protected under the Nature Conservation Decree (IUCN class Vulnerable; Rassi et al., 2001). The occurrence of the chequered blue is highly scattered in the southernmost Finland, and today the species exists in only five to ten areas (Somerma, 1997). The species has always been rare but the decline over the past decades has been suggested to result from forest succession after the abandonment of woodland pastures, lack of natural forest fires, residential development and quarrying of stone (Marttila et al., 2000). Our study population in Linnansaari National Park is likely to be the northernmost European population of the chequered blue, and one of the largest populations of the species in Finland.

The chequered blue is a specialist species, the larvae of which feed exclusively on the perennial herb Orpine (Sedum telephium L.) in Finland (Saarinen, 1995; Marttila et al., 2000). The species has been suggested to be facultative myrmecophilous (Traenkner \& Nuss, 2005). Exposed bedrock areas suitable for Orpine are usually small in area and occur patchily within the true island network in Linnansaari National Park. Species living in patchily distributed resources are generally assumed to have a metapopulation structure, which has also been documented for the chequered blue in another region in the southernmost Finland (Hanski, 1994; Saarinen, 1995). The metapopulation assumption is valid if the species has discrete local breeding populations, all local populations have a high risk of extinction and recolonization is possible (Hanski, 1999). The original metapopulation outlook emphasized the importance of patch area and isolation for patch occupancy (Thomas et al., 1992; Hanski, 1994). Lately, however, empirical research on butterfly metapopulations has demonstrated that habitat patch occupancy is also related to habitat quality (Dennis \& Eales, 1997; Thomas et al., 2001; Wahlberg et al., 2002; Krauss et al., 2005).

Most metapopulation studies have been conducted in habitat-island systems (e.g. Wahlberg et al., 2002; Krauss et al., 2005; Grundel \& Pavlovic, 2007), i.e. the matrix is not completely unsuitable for the species and can be used for feeding, resting and mating. The chequered blue system in Linnansaari is peculiar in this respect, as most of the matrix is water and thus truly hostile for the species. The aim of this study was to characterize the population structure and turnover of the chequered blue in Linnansaari National Park over a three year period.

\footnotetext{
* Present and corresponding address: Box 7044, Department of Ecology, SLU, SE-75007, Uppsala, Sweden; e-mail: atte.komonen@ekol.slu.se
} 


\section{MATERIAL AND METHODS}

\section{Study area}

Linnansaari National Park is situated in Lake Haukivesi in eastern Finland $\left(62^{\circ} 6^{\prime} \mathrm{N}, 28^{\circ} 30^{\prime} \mathrm{E}\right)$. The park is $40 \mathrm{~km}$ long and $5-10 \mathrm{~km}$ wide and runs from S-E to $\mathrm{N}-\mathrm{W}$. The area of the park is $38 \mathrm{~km}^{2}$, of which two thirds is water. There are over 130 islands most of which are covered by pine and herb-rich forests with scattered patches of exposed bedrock, particularly along the shorelines. This study was conducted in the core area of the park, in an island network covering $34 \mathrm{~km}^{2}$ (Table 1). The distribution of the chequered blue outside the park has not been mapped, but the species occurs immediately to the west of the park (ca. $1 \mathrm{~km}$ distance; pers. obs). There are no observations from the east, north or south of the park, and the landscapes in these areas lack exposed bedrock and thus are probably unsuitable for the species.

\section{Field survey}

Using topographic maps and aerial photographs, all islands were inspected to identify exposed bedrock. In the field inventory 2 June-2 July 2005, 76 potential islands were examined for suitable habitat patches; patch-based sampling protocol was adopted based on the patchy occurrence of exposed bedrock areas in which the host plant occurs, and given the knowledge about the species in Finland (Hanski, 1994; Saarinen, 1995; Marttila et al., 2000). Although most Orpines occur on patches of exposed bedrock, which are relatively easy to delineate, individual stems occur scattered along the rocky shorelines too. Based on the initial field visits, we thereby subjectively considered an area of exposed bedrock a patch suitable for the species, if it included at least 7 stems of the larval host plant. All Orpine stems and butterfly eggs were counted in 2005 .

\section{Patch delineation}

Without mark-recapture data to quantify butterfly movements it is generally difficult to determine whether two closelysituated patches are just different parts of the same habitat from the butterfly's perspective. Although the chequered blue is capable of long-distance movements $(1.5 \mathrm{~km}$ have been documented), mark-recapture study by Saarinen (1995) showed that $71 \%$ of the males and $50 \%$ of the females remained in a single patch, although there were other patches in the immediate vicinity (24 to $59 \mathrm{~m}$ ). Marttila et al. (2000) observed movements of marked individuals up to $250 \mathrm{~m}$. Both of these studies were conducted in a habitat patch network, not in the true island network as is the case in the present study. All "patches" that had center-to-centre distances less than $45 \mathrm{~m}(n=35)$ and had semiopen canopy and exposed bedrock in between, were pooled as one patch $(n=22)$; other patches had dense forest in between and thus they were considered separate patches. Total number of patches was 123 , and patch occupancy was determined by the presence of eggs. Islands-wise results are also presented when appropriate.

\section{Monitoring}

In 5-15 June 2006, all the patches sampled in 2005 were revisited to study the local population extinctions; estimates of colonizations are not reliable for this period, because in 2005 we had time only for a single visit per patch and thus there is likely to be many false negatives. In 2006, only the presence or absence of eggs was observed and all the populations that were empty in the initial survey were revisited 19 June to avoid false negatives. In 4-14 June 2007, presence or absence of eggs was observed again, and those patches that were found empty in the initial visit were revisited 19 and 20 June. In 2006 and 2007, 80 and $47 \%$, respectively, of the patches that were determined
TABLE 1. Characteristics of the chequered blue habitat patch network in Linnansaari National Park in eastern Finland. The area of the island network is estimated using convex hull. Medians are given with minimums and maximums in brackets. IFM $=$ Incidence Function Model.

Area of the island network $\left(\mathrm{km}^{2}\right) \quad 34$

$\begin{array}{ll}\text { Number of islands surveyed } & 76\end{array}$

Number of islands with habitat patches $\quad 42$

Number of patches

Median area of islands with patches (ha)

Median number of patches per island

Median patch area $\left(\mathrm{m}^{2}\right)$

Median nearest neighbor distance ( $\mathrm{m}$ )

$103(25-1076)$

Median IFM based connectivity

$0.048(0.000-0.496)$

Average \pm SD patch connectivity

$0.085 \pm 0.10$

unoccupied in the initial visit in early June were actually found occupied in the consecutive visit. To examine the egg laying dynamics over the flight season, we followed the egg laying in one of the best habitat patches 5 times in 2005 and 8 times in 2006. In each visit the number of eggs was counted from the same set of Orpine stems.

\section{Habitat variables}

Important factors influencing the patch occupancy of a butterfly are larval and adult food plants and thermal conditions (Krauss et al., 2005; Fred et al., 2006; Grundel \& Pavlovic, 2007). All Orpine stems in the patches were counted. Nectar plant abundance was estimated for each plant species that the chequered blue was observed to feed on regularly in Linnansaari (cf. plant list in Saarinen, 1993). These plant species were Fragaria vesca, Viola spp. (riviniana and tricolor pooled), Antennaria dioica, Convallaria majalis and Polygonatum odoratum. The abundance of each plant species was estimated on the $0-5$ scale $(0=$ absence, $5=$ very abundant $)$ and the sum of these species-specific estimates constituted the overall nectar plant abundance index $(\max .=25)$. The estimated index is robust and allows separating patches with high and low nectar plant abundance. The abundance was estimated by the same person. Thermal conditions were estimated using patch exposition. Exposition was determined using compass bearing with 10degree accuracy. Patch sizes were estimated based on rectangular area covering the open area with host plants.

\section{Connectivity}

In the metapopulation conditions the exact spatial location of patches in relation to other patches has been identified to be an important factor affecting patch occupancy (Hanski, 1994). Patch location was determined by GPS coordinates taken from the center of each patch. We used the incidence function model measure of patch connectivity (Hanski, 1994; Moilanen \& Nieminen, 2002), which takes into account distances to all potential source patches:

$$
S_{i}=\sum_{i \neq j} \exp \left(-a d_{i j}\right) A_{j}^{b}
$$

This measure uses a negative exponential dispersal kernel, with parameter $\alpha$ scaling the effect of distance to migration $(1 / \alpha$ is the average dispersal distance), $d_{i j}$ is the distance between patches $i$ (focal patch) and $j$ (donor patch), $A_{j}$ is the area of patch $j$ and $b$ scales the donor population size with patch area. Here we used $b=0.3$, which is typical for butterfly metapopulations and has been used for the chequered blue (Moilanen \& Nieminen, 2002). The importance of connectivity measure in explaining turnover events was evaluated using the average dis- 


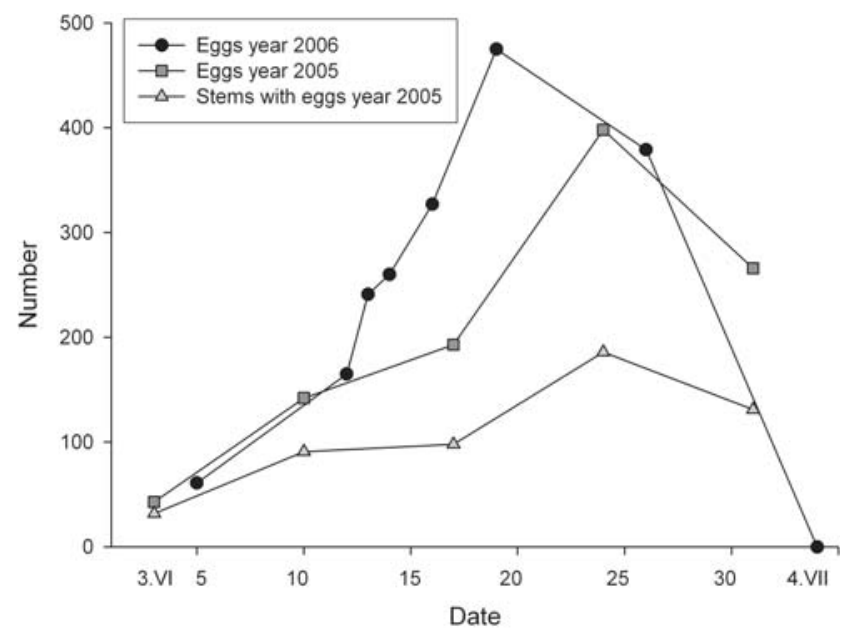

Fig. 1. The within-season dynamics of the number of eggs laid by the chequered blue in June-July 2005 and 2006, and the number of stems with eggs in 2005 in one of the best patches in Linnansaari National Park.

persal distances of $50 \mathrm{~m}, 100 \mathrm{~m}$ and $300 \mathrm{~m}$, which are in the range of known average dispersal distances of the species (Saarinen, 1995; Marttila et al., 2000).

\section{Analyses}

We used a logistic regression to analyse the influence of patch area, connectivity, host plant number, nectar plant abundance and exposition on the local patch occupancy $(1=$ habitat occupied for three years; $0=$ habitat not occupied either in 2006 or 2007; see below). Significance of individual factors was determined by omitting the given term and comparing the change in deviance to the full model including all variables. Change in deviance follows $\chi^{2}$-distribution with $\mathrm{df}=1$. Goodness-of-fit was evaluated using Hosmer and Lemeshow test. Due to high probability of false negatives in 2005 (see above), we considered conservatively that all the empty patches in 2005 were false negatives, and thus patches which were occupied in 2006 and 2007 were also considered occupied in 2005. This could slightly underestimate turnover rate. Turnover was analysed both at the island and patch scale. Connectivity is not applied at the island scale as one island may host many patches, and thus there is no single connectivity measure that would adequately describe the situation for all patches.

\section{RESULTS}

\section{Network characteristics and egg laying dynamics}

We observed 30,633 host plant stems, 135 adult butterflies and 1,915 eggs in 123 habitat patches in 2005 (excluding the over-season monitoring of egg laying in one patch with a maximum daily count of 402 eggs). Most patches were small. The size distribution of patches followed a lognormal distribution with an average area of $748 \mathrm{~m}^{2}$ (Kolmogorov-Smirnov $=0.18, \mathrm{n}=123, \mathrm{p}=0.86$; Table 1). The average number of host plants and eggs varied greatly between patches (mean \pm S.E. $=249.1 \pm$ 22.3 , med. $=150$, $\max .=1009$, and $15.6 \pm 2.1,6,165$, respectively). The overall observed number of eggs is an underestimate, as it is based on a single visit only (cf. Fig. 1). In the monitoring of egg number over the flight season, the maximum number of eggs per count in a single patch was 398 and 475 in 2005 and 2006, respec-

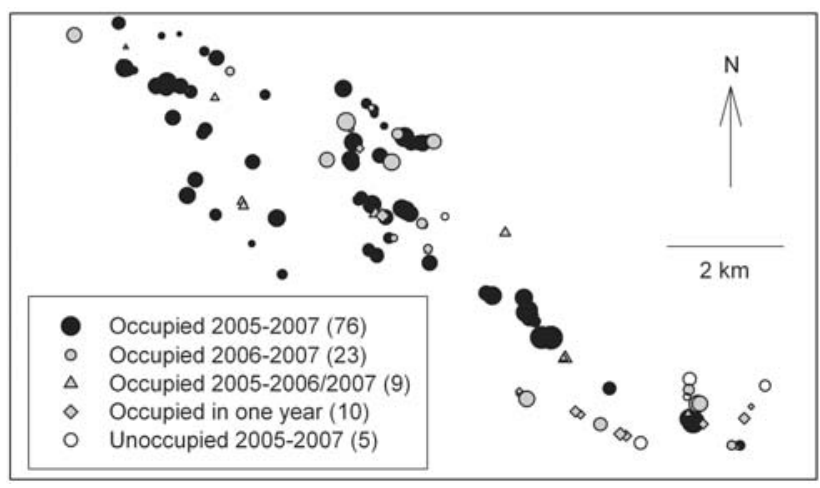

Fig. 2. The occurrence of the chequered blue butterfly in a network of 123 habitat patches in 2005-2007 in Linnansaari National Park. The patches in which the species occurred in two years were divided in two classes (occupied 2005 and 2006 or 2007; occupied 2006 and 2007) due to possible high number of false negatives in 2005 (see main text for details). Symbol sizes reflect the habitat patch area ( $\log _{10}$-transformed). The number of patches in each class is given in parentheses.

tively. During a single day between 12 and 13 June 2006, 76 eggs were laid. There was significant linear relationship between patch size and the number of host plant stems $\left(\mathrm{r}=0.50, \mathrm{r}^{2}=0.25, \mathrm{n}=123, \mathrm{p}<0.001\right.$; both variables were log-transformed).

\section{Island occupancy and turnover}

Of the 76 islands that were checked for the chequered blue, $54 \%(\mathrm{n}=41)$ were suitable for the species (Table 1). The total area of the islands with suitable habitat for the chequered blue was 1273 ha, of which only 9.2 ha $(0.7 \%)$ was delineated as habitat. Of the islands, 73,85 and 88\% were occupied in 2005, 2006 and 2007, respectively; two islands remained empty during the three years. The annual population turnover rate was $17 \%$ between 2006 and 2007 , with a $7 \%$ extinction and $10 \%$ colonization rate. The extinction rate was 3\% between 2005 and 2006; colonization rate is not reliable for these years, as already mentioned. Turnover events took place in 7 islands, which had 1-2 suitable habitat patches (total 9) with an average area \pm SE of $50.2 \pm 9.0 \mathrm{~m}^{2}$. Six of these islands were only $0.6-3$ ha in area, but one was as large as 28 ha. Fifteen islands had only 1 habitat patch, 23 islands had 2-5 patches and 4 islands had $\geq 8$ patches, and of these islands 47,70 and $100 \%$, respectively, were occupied during all three years. The larger the total area of patches in an island, the more likely it was that an island was occupied over the three year period (logistic regression $\chi^{2}=12.62, \mathrm{n}=41, \mathrm{p}<0.001$, Nagelkerke $\mathrm{r}^{2}=$ $0.40)$. Host plant number did not have a significant influence on the island occupancy.

\section{Patch occupancy and turnover}

The 41 studied islands included 123 habitat patches in 2005, and 121 patches in 2006 and 2007 (host plant disappear from two patches), of which $69 \%$ were occupied in $2005,88 \%$ in 2006 and $90 \%$ in 2007 (Fig. 2). Five patches remained empty and 76 patches occupied during the three years. An additional 23 patches of the ones that 
TABLE 2. Relationship between patch occupancy and habitat variables, based on a logistic regression model. $\chi^{2}$ gives the change in full model deviance when the given term is dropped from the model, and follows $\chi^{2}$-distribution with $\mathrm{df}=1$. Connectivity 50 assumes an average $50 \mathrm{~m}$ dispersal distance and the other two connectivity measures 100 and $300 \mathrm{~m}$ dispersal distances.

\begin{tabular}{lcc}
\hline Variable & $\chi^{2}$ & $\mathrm{p}$ \\
\hline Area & 7.286 & $<0.01$ \\
Connectivity $50^{*}$ & 8.048 & $<0.01$ \\
Host plant & 2.183 & $\mathrm{~ns}$ \\
Nectar plant & 0.671 & $\mathrm{~ns}$ \\
Exposition & 0.758 & $\mathrm{~ns}$ \\
Connectivity $100^{*}$ & 5.766 & $<0.05$ \\
Connectivity $300^{*}$ & 3.885 & $<0.05$ \\
\hline
\end{tabular}

* Full model deviances using dispersal distances. $50 \mathrm{~m}: \chi^{2}=$ 22.26, d.f. $=5, \mathrm{p}<0.001, \mathrm{R}^{2}=0.27 ; 100 \mathrm{~m}: \chi^{2}=19.98$, d.f. $=5$, $\mathrm{p}=0.001, \mathrm{R}^{2}=0.24 ; 300 \mathrm{~m}: \chi^{2}=18.10$, d.f. $=5, \mathrm{p}<0.01, \mathrm{R}^{2}=$ 0.22 .

were empty in 2005 were occupied both in 2006 and 2007, and many of these could have been actually occupied in 2005. There were five local extinctions between 2005 and 2006, one of which resulted from the disappearance of the host plant. The population turnover rate between 2006 and 2007 was 16\%, with an extinction and colonization rate of $7 \%$ and $9 \%$, respectively. Patch area and connectivity increased the likelihood of a patch being occupied over the three year period (Table 2, Fig. 3). The number of host plant stems, nectar plants or exposition did not significantly influence patch occupancy. The significant effect of connectivity remained if a 100 or $300 \mathrm{~m}$ average dispersal distance was assumed.

\section{DISCUSSION}

\section{Habitat occupancy}

The area delineated as suitable habitat covers only $0.7 \%$ of the area of the suitable islands. Individual patches are generally very small in size, although there is plenty of variation in patch area and host plant number between patches. Most of the matrix is water and thus truly hostile for feeding, resting, mating and reproduction of the species, which is often not the case in habitat-island type metapopulations (Wahlberg et al., 2002; Krauss et al., 2005; Grundel \& Pavlovic, 2007). Yet, the incidence of the chequered blue on the islands was high, close to $90 \%$ in 2006 and 2007. The species occupied also a high proportion of the patches: $69-90 \%$, the lower percentage being clearly an underestimate. The large fraction of occupied patches indicates that if the exposed bedrock area is suitable for the Orpine it is also suitable for the chequered blue reproduction. The long-term persistence of small isolated populations has been documented for the chequered blue (Henriksen \& Kreutzer, 1982; Saarinen, 1995; Marttila et al., 2000) and for another threatened blue species, Cupido minimus (Krauss et al., 2004). Hanski (1994) suggested a metapopulation is viable if

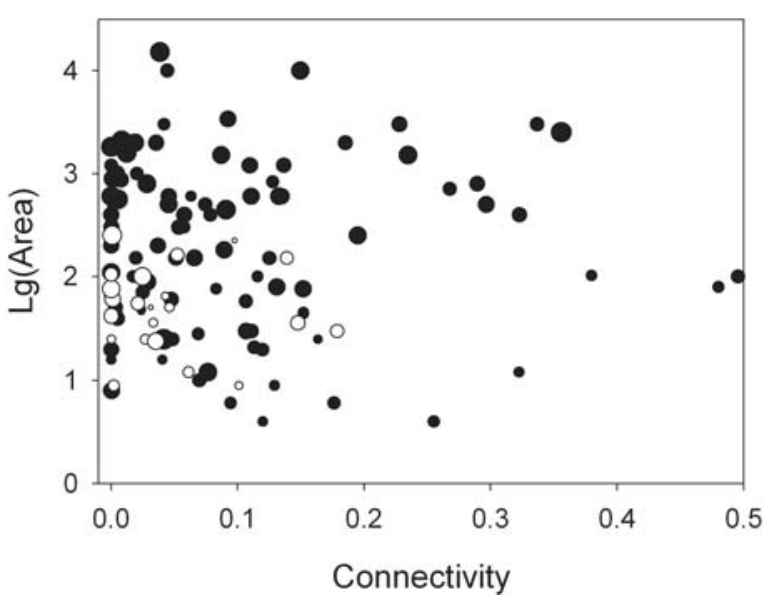

Fig. 3. The relationship between patch area, connectivity and host plant number on the patch occupancy over the three year period. Symbol size indicates host plant abundance $\left(\log _{10^{-}}\right.$ transformed). Black circles indicate occupied patches.

about $50 \%$ of the patches are occupied and this was corroborated by Vos et al. (2001).

In a habitat patch network of roughly similar area (21 $\mathrm{km}^{2}, 72$ patches) in southern Finland, the chequered blue occupied $61-78 \%$ of the suitable patches (Saarinen, 1995). Thomas et al. (2001) reported 62\% patch occupancy for the adonis blue (95 patches) and Krauss et al. (2005) 71\% patch occupancy for the chalkhill blue (124 patches) with much larger sizes and greater isolation of individual patches in both studies. Close to $90 \%$ occupancy levels have been observed for the Karner blue, but in this study patches were defined if there were $>10 \mathrm{~m}$ gaps between wild lupine cover (Grundel \& Pavlovic, 2007). The above comparisons show that the observed patch occupancy for the chequered blue is in line with other studies on blue butterflies in a variety of similarsized patch networks. The somewhat higher occupancy can be related to the shorter distances between patches, although the patch sizes are much smaller for the chequered blue than documented for the other species.

\section{Population turnover}

Although the island and patch occupancy of the species was high, extinction and recolonization events were regularly observed. The turnover events took place in islands that were small in size (under 1 ha mostly) and harbored typically one or two habitat patches. Island-wise extinction and colonization rates were in balance. In larger islands, it is possible that the smaller patches have rescue effect from the other patches. Turnover events took mostly place in patches that are small and isolated, which is in accordance with the chequered blue system in southern Finland (Hanski, 1994; Saarinen, 1995) and with the Karner blue system in the eastern United States (Grundel \& Pavlovic, 2007). Other studies on blue butterflies have documented varying importance of area, isolation and host plant density (Thomas et al., 2001; Krauss et al., 2005; Rabasa et al., 2007). Also, it has been suggested that higher connectivity could compensate for lower habitat quality in the small blue metapopulation in 
Bavaria, Germany (Binzenhöfer et al., 2007). It should be noted, however, that the connectivity measures vary between some of the studies, which makes it inappropriate to directly compare them. In Linnansaari, the patchwise extinction and colonization rates were also in balance. The observed turnover rate $(16 \%)$ is less than has been observed for the chequered blue metapopulation in southern Finland (31\%; Saarinen, 1995).

\section{Influence of host and nectar plants}

The fact that patch area and connectivity, but not host plant number or nectar plant abundance, explained the persistence of local populations indicates that stochastic extinction-colonization dynamics play a greater role in this system. This does not mean, however, that host and nectar plants are unimportant as they are the prerequisites for successful reproduction, and have been identified as important determinants of patch occupancy in butterflies (Dennis \& Eales, 1997; Thomas et al., 2001; Wahlberg et al., 2002; Krauss et al., 2004, 2005; Binzenhöfer et al., 2007; Grundel \& Pavlovic, 2007). Indeed, in this study the host plant number correlated significantly with patch area, although there was large variation in average plant number (see also Krauss et al., 2005; Grundel \& Pavlovic, 2007; Rabasa et al., 2007). There is likely to be some minimum number (size of individual plants or density of stems) of Orpines per patch to enable successful reproduction: the larvae of the chequered blue eat the Orpine leaves completely and in very small patches a lack of food may become a problem. Larval feeding also hinders flowering by breaking off the flower stems, which may influence the plant dynamics. As a perennial species, however, Orpine can recover. It is possible that the importance of host plant density becomes apparent if egg number, instead of presence or absence, is used in analyses, but there is also general evidence of poor correlation between the density of focal species and habitat quality (van Horne, 1983; Brawn \& Robinson, 1996).

Different life-history stages need different resources and this is known to influence the movement and consequent spatial configuration of butterflies (Brommer \& Fred, 1999; Fred et al., 2006). There was a great deal of variation in both host plant and nectar plant abundance, and there was no clear linkage between their number and the occupancy of the chequered blue. In one patch that was devoid of nectar plants we observed 51 eggs in 18 stems, indicating that these two crucial elements need not always coincide. The general lack of explanatory power of the host and nectar plant abundance in habitat patches also calls for refinement of the habitat-based approach, as suggested by Dennis et al. (2006). Nectar plants outside the exposed bedrock patches may be crucial for the survival and reproduction of the chequered blue.

Habitat quality is dynamic, resulting mostly from deterministic succession and stochastic, non-successional host plant dynamics (Warren, 1991; Thomas \& Harrison, 1992; Wahlberg et al., 2002). Chequered blue occupies exposed bedrock areas, which are likely to be less affected by within patch succession, compared with clearcuts, grassland or meadows (Wahlberg et al., 2002;
Krauss et al., 2005; Binzenhöfer et al., 2007). However, the host plant dynamics is likely to be very important for short-term butterfly dynamics, compared with the successional dynamics of the patches themselves and their immediate surroundings. Orpine went extinct from two small patches between 2005 and 2006, $300 \mathrm{~m}^{2}$ and 119 stems, and $9 \mathrm{~m}^{2}$ and 18 stems, respectively. Although we did not study the dynamics of the host plant, our observations suggest that the dynamics of the host plant may be one important driver of the local dynamics of the butterfly, and quantifying the host plant dynamics deserves further study. Host plant quality may also be of importance, as it has been identified affecting oviposition preference and larval performance of lycaenid butterflies (Goverde et al., 1999; Forister, 2004, 2005).

\section{Evidence for metapopulation}

Does the chequered blue in Linnansaari National Park meet metapopulation assumptions or is there evidence for a patchy or non-equilibrium population sensu Harrison \& Taylor (1997)? As the recolonizations show, butterflies can readily move between island and habitat patches, so the non-equilibrium population can be overruled. Given the large area of the patch network, truly hostile matrix and isolation of many individual patches, it is also unlikely that there would be one fully interacting population. The observed extinctions show that many of the small populations are not persistent suggesting that patchy population can be overruled too. The observed balance in extinction and colonization rates indicates that the chequered blue system in Linnansaari meets metapopulation assumptions. However, only long term monitoring will reveal whether the largest populations can go extinct due to stochastic factors, so currently it is impossible to differentiate between the mainland-island and the classical Levin's metapopulation structure (see Hanski, 1999); indeed, there can be elements of both in different parts of the network. In any case, the role of the largest islands and subpopulations therein for the long-term metapopulation persistence can only be evaluated via long-term monitoring of the system for which the present study provides a good basis (cf. Rabasa et al., 2007).

The chequered blue system in Linnansaari is very similar in terms of high patch occupancy and low population turnover rate to the metapopulation of the species in southern Finland and to the metapopulations of many other blue butterflies. All this indicates that the Linnansaari metapopulation is not in immediate risk of extinction, particularly as the species has survived in the park for decades. As Linnansaari National Park hosts the northernmost European population of the chequered blue, monitoring of its population could also provide information on wider environmental changes taking place due to climate change.

ACKNOWLEDGEMENTS. We thank Forest and Park Service (Savonlinna) for providing financial support and field facilities for the study, and O. Herranen for invaluable help in Oravi. Regional Environmental Agency of Etelä-Savo provided permit to study the protected species. O. Ovaskainen kindly calculated the connectivity measures and comments by N. Wahlberg 
improved the manuscript. The study was financially supported by Forest and Park Service, the Academy of Finland (the Center of Excellence in Evolutionary Ecology) and the Finnish Lepidopterological Society.

\section{REFERENCES}

Binzenhöfer B., Biedermann R., Settele J. \& Schröder B. 2007: Connectivity compensates for low habitat quality and small patch size in the butterfly Cupido minimus. Ecol. Res. DOI 10.1007/s11284-007-0376-x.

BRAWN J.D. \& RoBinson S.K. 1996: Source-sink population dynamics may complicate the interpretation of long-term census data. Ecology 77: 3-12.

Brommer J.E. \& Fred M.S. 1999: Movement of the Apollo butterfly (Parnassius apollo) related to host-plant and nectar plant patches. Ecol. Entomol. 24: 125-131.

Dennis R.L.H. \& Eales H.T. 1997: Patch occupancy in Coenonympha tullia (Müller, 1764) (Lepidoptera: Satyrinae): habitat quality matters as much as patch size and isolation. $J$. Insect Conserv. 1: 167-176.

DenNis R.L.H., ShreEve T.G. \& van Dyck H. 2006: Habitats and resources: the need for a resource-based definition to conserve butterflies. Biodiv. Conserv. 15: 1943-1966.

FORISTER M.L. 2004: Oviposition preference and larval performance within a diverging lineage of lycaenid butterflies. Ecol. Entomol. 29: 264-272.

Forister M.L. 2005: Influence of host plant phenology on Mitoura nelsoni (Lepidoptera: Lycaenidae). Ann. Entomol. Soc. Am. 98: 295-301.

Fred M.S., O’Hara R.B. \& Brommer J.E. 2006: Consequences of the spatial configuration of resources for the distribution and dynamics of the endangered Parnassius apollo butterfly. Biol. Conserv. 130: 183-192.

Goverde M., Bazin A., Shykoff J.A. \& Erhardt A. 1999: Influence of leaf chemistry of Lotus corniculatus (Fabaceae) on larval development of Polyommatus icarus (Lepidoptera, Lycaenidae): effects of elevated $\mathrm{CO}_{2}$ and plant genotype. Funct. Ecol. 13: 801-810.

Grundel R. \& PAVlovic N.B. 2007: Resource availability, matrix quality, microclimate, and spatial pattern as predictors of patch use by the Karner blue butterfly. Biol. Conserv. 135: $135-144$.

HANSKI I. 1994: A practical model of metapopulation dynamics. J. Anim. Ecol. 63: 151-162.

HANSKI I. 1999: Metapopulation Ecology. Oxford University Press, 313 pp.

HARRISON S. \& TAYLOR A.D. 1997: Empirical evidence for metapopulation dynamics. In Hanski I.A. \& Gilpin M.E. (eds): Metapopulation Biology: Ecology, Genetics, and Evolution. Academic Press, San Diego, pp. 27-42.

Henriksen H.J. \& Kreutzer I.B. 1982: The Butterflies of Scandinavia in Nature. Skandinavisk Bogförlag, Odense, 215 pp.

Krauss J., Steffan-Dewenter I. \& TscharntKe T. 2004: Landscape occupancy and local population size depends on host plant distribution in the butterfly Cupido minimus. Biol. Conserv. 120: 355-361.

Krauss J., Steffan-Dewenter I., Müller C.B. \& Tscharntke T. 2005: Relative importance of resource quantity, isolation and habitat quality for landscape distribution of a monophagous butterfly. Ecography 28: 465-474.

KudRnA O. 2002: The distribution atlas of European butterflies. Oedippus 20: 1-343.

Marttila O., SaArinen K. \& Marttila P. 2000: Six years from passing bell to recovery: Habitat restoration of the threatened Chequered Blue Butterfly (Scolitantides orion) in SE Finland. Entomol. Fenn. 11: 113-117.

Moilanen A. \& Nieminen M. 2002: Simple connectivity measures in spatial ecology. Ecology 83: 1131-1145.

Rabasa S.G., Gutiérrez D. \& Escudero A. 2007: Metapopulation structure and habitat quality in modelling dispersal in the butterfly Iolana iolas. Oikos 116: 793-806.

Rassi P., Alanen A., Kanerva T. \& Mannerkoski I. 2001: The 2000 Red List of Finnish Species. Ministry of the Environment, Finnish Environment Institute, Helsinki, 432 pp. [in Finnish, English abstr.].

SAARINEN P. 1993: The Ecology and Distribution of Scolitantides orion in Lohja Region. MSc thesis, University of Helsinki, 61 pp. [in Finnish].

SAARINEN P. 1995: The ecology of Scolitantides orion (Lepidoptera: Lycaenidae) in a metapopulation in southern Finland 1991-92. Baptria 20: 195-198 [in Finnish, English abstr.]

Somerma P. 1997: Threatened Butterflies in Finland. Suomen ympäristökeskus, Suomen Perhostutkijain Seura, Helsinki, 336 pp. [in Finnish].

THOMAS C.D. \& HARRISON S. 1992: Spatial dynamics of a patchily distributed butterfly species. J. Anim. Ecol. 61: 437-446.

Thomas C.D., Thomas J.A. \& WARREN M.S. 1992: Distributions of occupied and vacant butterfly habitats in fragmented landscapes. Oecologia 92: 563-567.

Thomas J.A., Bourn N.A.D., Clarke R.T., Stewart K.E., Simcox D.J., Pearman G.S., Curtis R. \& Goodger B. 2001: The quality and isolation of habitat patches both determine where butterflies persist in fragmented landscapes. Proc. R. Soc. Lond. (B) 268: 1791-1796.

Traenkner A. \& Nuss M. 2005: Risk spreading in the voltinism of Scolitantides orion orion (Pallas, 1771) (Lycaenidae). Nota Lepidop. 28: 55-64.

VAN HoRNe B. 1983: Density as a misleading indicator of habitat quality. J. Wildlife Manag. 47: 893-901.

Van SwaAy C.A.M. \& Warren M.S. 1999: Red Data Book of European Butterflies (Rhopalocera). Nature and Environment, No. 99, Council of Europe Publishing, Strasbourg, 260 pp.

Vos C.C., Verboom J., Opdam P.F.M. \& Ter Braak C.J.F. 2001: Toward ecologically scaled landscape indices. Am. Nat. 183: 24-41.

Wahlberg N., Klemetti T. \& Hanski I. 2002: Dynamic populations in a dynamic landscape: the metapopulation structure of the marsh fritillary butterfly. Ecography 25: 224-232.

WARREN M.S. 1991: The successful conservation of an endangered species, the heath fritillary butterfly Mellicta athalia, in Britain (UK). Biol. Conserv. 55: 37-56.

Received October 29, 2007; revised and accepted December 4, 2007 